\title{
La seducción del mal: la mujer vampiro en la literatura romántica
}

\author{
Golrokh EETESSAM PÁRRAGA \\ Universidad Complutense de Madrid \\ golyep@gmail.com
}

\begin{abstract}
RESUMEN
La figura de la mujer vampiro invade los relatos y poemas del Romanticismo europeo representando la seducción de la oscuridad y del mal. La femme fatale vampírica reúne en sí las principales características del mito de la mujer peligrosa para el hombre, desde LeFanu hasta Miller, la fémina delicada que seduce y mata por placer ha fascinado y aterrado por igual a los grandes escritores decimonónicos.
\end{abstract}

Palabras clave: Mujer vampiro, Romanticismo, arquetipo, mitología.

\begin{abstract}
The figure of the vampire woman invades the tales and poems of the European Romanticism representing the seduction of the dark and evil. The femme fatale vampire itself meets the main features of the myth of the dangerous woman to man, from LeFanu to Miller, where the delicate female who seduces and kills for pleasure has fascinated and terrified the great nineteenth-century writers.
\end{abstract}

Key words: Vampire woman, Romanticism, archetype, mythology.

La historia de la mujer vampiro es la historia del mal imperecedero, siempre seduciendo y tentando al bien, y es, también, la historia del miedo a lo oculto, a lo diferente, en cualquiera de las distintas interpretaciones (social, histórica, literaria) que podamos encontrar.

Aunque las primeras historias de vampiras tal y como hoy las conocemos nacieron con la novela gótica del siglo XIX, no resulta difícil rastrear este arquetipo femenino a lo largo de la literatura, la mitología y la superstición, desde la antigüedad clásica hasta el momento en el que dicha figura literaria aprehendió sus cualidades definitivas en el relato "Carmilla" de LeFanu. 
Son diversas las figuras clásicas que reúnen en sí las características iniciales de este personaje tipo; y todas ellas heredan sus rasgos de un tronco común. Arpías, estriges, empusas y lamias ${ }^{1}$ presentan afinidades con Carmilla y Clarimonda, por ejemplo. Y todas ellas son, a su vez, hermanas ilegítimas de Lilith, la encarnación de la nocturnidad, de la lascivia y el mal femenino del que se alimentó durante siglos la imaginería de la mujer pérfida y cruel hasta que llegó el modo decimonónico de ver el mundo, el perfecto caldo de cultivo en el que la mujer fatal -peligrosa, sádica y hambrienta- toma cuerpo y nombre en los relatos de vampiros.

Desde los albores de la mitología, podemos rastrear cómo en diferentes religiones y culturas se hallan diversas criaturas femeninas que beben la sangre de los hombres u otros fluidos, como es el caso de la Lilit sumeria y babilónica que, en el mundo hebreo, se transforma en una buscadora de todo el semen masculino que no acaba en el único lugar permitido, la matriz de la esposa. Ella reúne ya los elementos fundamentales presentes con posterioridad en los motivos vampíricos, como son un carácter preeminentemente nocturno y el ansia de sangre.

La construcción del tipo de la vampira se erige sobre dos puntos paralelos: la bruja, de las que toma sus poderes sobrenaturales y con la que, ocasionalmente, pueden establecerse claros paralelismos ${ }^{2}$, como veremos más adelante entre $L a$ Muerta Enamorada de Gautier y El Monje, de Lewis; y la femme fatale, quien presta su iniciativa, su letal seducción y la oscuridad inconfesable de sus últimas intenciones. No podemos decir, en este sentido, que exista una sustitución de la mujer fatal o de la bruja por la vampira. En este caso, usaremos lo que Jan Perkowski llamó el "Daemon Contamination"3, un proceso de contaminación mutuo, una influencia recíproca que se da a través de los tiempos entre las distintas criaturas demoníacas de la mitología, el folclore y la literatura.

Para Lucendo Lacal,

\footnotetext{
${ }^{1}$ Según enumera F. Muñoz Acebes (2000), pp. 116-117, las lamias recuperaban "su antigua belleza con la sangre de sus víctimas. Empusa era una criatura demoníaca de pies de bronce que podía transformarse en bella mujer para seducir a los hombres durante el sueño. Las estrigas son igualmente figuras femeninas con cuerpo de pájaro que succionan la sangre de los recién nacidos o de los jóvenes durante el sueño. El denominador común es en todos los casos el de una criatura femenina bastante sanguinaria, pero en el caso de las lamias, éstas incorporan en su mito el carácter vivificante de la sangre. Hay que añadir que Flavio Filóstrato (ca. 170-245) en su Vida de Apolonio de Tiana incorpora el motivo de la lamia en su obra, constituyendo por tanto uno de los primeros relatos vampíricos de la literatura occidental".

2 Diversos estudiosos, entre los que se encuentran Ibarlucía y Castelló-Joubert, sostienen que el término griego brucolaco o vrucolaca, que puede traducirse como "mordedor", "devorador" o "roedor", quizá contenga la raíz etimológica de la palabra "bruja", lo que explicaría la relación de coexistencia entre ambos personajes.

${ }^{3}$ J. Perkowski (1989), p. 70.
} 
el vampiro pasa por un proceso de transformación a través de los diferentes contextos en los que actúa: el folclore crea un monstruo a través de una superstición, una superstición que a su vez se simplifica en un tema de dominio popular a través de un estereotipo y que desde su difusión fuera del contexto original pasa a la ficción, y en ese nuevo contexto va a servir para señalar un nuevo tipo de realidad ${ }^{4}$.

La construcción del estereotipo femenino llegó a la literatura en la segunda mitad del siglo XIX, cuando la figura del dandy vampírico dominante al estilo del Lord Ruthven de Polidori comienza a dejar paso a la mujer demoníaca.

Sin embargo, este intercambio de papeles puede rastrearse en algunas obras anteriores, como es el caso de la balada de Goethe, La Novia de Corinto (1797), en el que la mujer vampiro se apropia de la fuerza del personaje de tipo byroniano y acarrea la desgracia y la muerte a todo aquel que osa acercarse a ella.

Si tenemos en cuenta las características de la mujer malvada presentes en la historia literaria hasta este momento, resultaba del todo inevitable la asociación entre estos dos elementos tan seductores para el artista romántico: la belleza femenina y la muerte. Eros y Tánatos. La no muerta de piel blanca, magnéticos ojos verdes y cabellera roja, como indican los cánones, que seduce, pervierte $\mathrm{y}$, finalmente, mata a su víctima.

En el romanticismo, como señala Mario Praz "de los mismos motivos que deberían provocar desagrado [...] brota un nuevo sentido de belleza engañosa y contaminada, un estremecimiento nuevo". 5

Otro gran escritor de lo fantástico aterrador, Poe, en La filosofía de la composición, reconoce de forma explícita que la muerte de una mujer bella es el mejor tema poético que puede encontrarse

cuando se halla más estrechamente ligado a la Belleza: la muerte, por tanto, de una mujer hermosa es, sin ningún género de dudas, el tema más poético del mundo; y del mismo modo tampoco cabe dudar que los labios más aptos para expresar este tema son los de un amante despojado de su amada. ${ }^{6}$

Para los románticos la belleza suprema es la belleza maldita, y hay cientos de textos que lo atestiguan. Entre los más conocidos destacan el poema de Shelley sobre Medusa, inspirado por el cuadro atribuido a Da Vinci que conoció en la galería Uffizi; Baudelaire en cualquiera de sus flores del mal, o los novelistas de lo horrendo como Mirabeau en Les jardin de supplices o Lewis en El Monje.

\footnotetext{
${ }^{4}$ S. Lucendo Lacal (2009), p. 10.

${ }^{5}$ M. Praz (1999), p. 66.

${ }^{6}$ E. A. Poe (2001), p. 47.
} 
Durante este siglo, Muerte y Belleza "se confunden en una sola hermana bifronte de fatal belleza, en la que se mezclan la corrupción y la melancolía" ${ }^{\text {", }}$ un concepto que, si bien fue tratado en estos momentos por primera vez con semejante profundidad, ha aparecido ya anteriormente a lo largo de la historia de la literatura en momentos y escritores puntuales pero con destacable constancia.

Pese a que el arquetipo se construyó y se definió en el literatura europea de fin de siècle es cierto que fue la literatura norteamericana de terror, abanderada por autores como Poe y Lovecraft, la que con más frecuencia recurrió a esta figura prototípica y concretó en torno suyo todo un subgénero literario que aún hoy en día sigue cosechando grandes éxitos y despertando gran interés en todo tipo de lectores.

En estas páginas, sin embargo, nos centraremos en el origen y nacimiento del tópico decimonónico, rastreando sus posibles influencias y analizando sus diversas variantes.

Aunque no vaya a ser el hilo principal de este trabajo, no podemos olvidar que el personaje de la vampira indica una serie de cambios con respecto al lugar de la mujer en el mundo de la época. Son muchos quienes han visto en su papel un reflejo de la creciente importancia y autonomía femenina en la vida social y política. Sin embargo, la clara monstruosidad de estas representaciones (crueles, asesinas, malvadas...) nos conduce inevitablemente hacia el análisis de este papel desde un punto de vista claramente negativo.

La imagen del vampiro se ha ido configurando en base a las características que les atribuyen las leyendas populares y, con posterioridad, los textos literarios. La palidez extrema, la frialdad de la piel y la sed de sangre son los rasgos comunes que presentan vampiros de ambos sexos.

Si bien el componente carnal siempre ha estado presente -recordemos las mitológicas figuras de súcubos e íncubos que, a hurtadillas, se adentraban en las alcobas de hombres y mujeres desprevenidos para saciar sus deseos sexuales y su instinto depredador- es en la literatura cuando entra en juego el poder de la seducción femenina. La vampira, como estereotipo de devoradora sexual, nace fundamentalmente en el siglo XIX aunque se desarrollará a lo largo del siglo XX, gracias, sobre todo, a su difusión en el cine. Sin embargo, su imagen como mujer dominante y peligrosa conforma un fenómeno anterior, más amplio y, como ya hemos apuntado, no restringido en absoluto a la ficción victoriana.

Para construir su personaje y el ambiente que le rodea, Goethe cuenta con diversos antecedentes literarios. Es más que probable que conociera una de las primeras apariciones de este motivo en la literatura alemana, más concretamente en el poema de Ossenfelder de 1748, "El Vampiro" (Mein Liebes Mägdchen glaubet), en el que se acuña por primera vez el ya tan familiar término "vampiro".

${ }^{7}$ M. Praz (1999), p. 80 
La más importante de sus influencias es, sin duda, la clásica La novia de Amfipolis de Flegón de Tralles, un cuento tradicional de fantasmas que es transformado por Goethe en una historia de vampiros. En la balada del autor alemán, la protagonista es, contrariamente a lo que sucede en el relato de Flegón, la causa directa de la muerte del amado, al que ha chupado la sangre del corazón, convirtiéndose en una amenaza aterradora para todo el que la rodea ${ }^{8}$.

La balada de Goethe alcanza puntos críticos en la historia literaria no sólo porque dé forma y definición a las características propias del vampiro en una poderosa figura femenina, sino porque incorpora nuevos rasgos a los que posteriormente recurrirán otros autores para dotar a sus terribles personajes de este tipo de tristeza seductora tan habitual ya en el mundo de los no muertos. Como señala Mario Praz, "a propósito de La esposa de Corinto, de Goethe, Madame de Staël advertía una «mezcla de amor y espanto», la "voluptuosidad fúnebre» que emanaba de la escena en la que «el amor se aliaba con la tumba, la misma belleza no parecía más que una horrorosa aparición»".

En el poema del autor alemán el lado más malvado de la criatura se muestra sólo tras la muerte del amado. Su arrepentimiento y sus sentimientos humanos (reprocha a su madre el pacto que ésta, siendo joven y estando enferma, realizó para entregar a su hija a cambio de recuperar su lozanía ${ }^{10}$ ) la alejan de la figura aterradora tan habitual en la superstición popular. Son también estas características las que la hacen tan distinta del tipo de mujer malvada, sádica y cruel que aparecerá años después en Gautier, o en los poemas de Baudelaire. Con el ambiente decimonónico, las historias de vampiros dejaron a un lado sus referentes a denuncias políticas para centrarse en el lado oscuro, erótico, desazonador y sensual de la seducción del mal.

Pese a ello, la mujer vampiro no ha perdido toda esa carga contestataria hacia la moral cristiana y su peligro principal sigue haciendo referencia al pecado original. La vampira es promiscua, agresiva, activa y egoísta, características que chocan de pleno con la idea cristiana de la mujer-moral. Como señala Lucendo Lacal "las

\footnotetext{
${ }^{8}$ Para muchos, Goethe se inspiró en la historia de Menipo Licio y la Empusa, referida por Filóstrato en el libro cuarto de su Vida de Apolonio de Tiana (II d. C.): una bella mujer seduce a un joven para que se case con ella, en la boda se dan cuenta de que es una Empusa, y al nombrarla hasta sus vestidos, su casa y su cuerpo se desvanecen. En la mitología griega, las Empusas formaban el séquito de Hécate, la diosa de la muerte. Adoptando la figura de una hermosa doncella, solían acostarse con los hombres durante la noche y chuparles sus fuerzas vitales hasta hacerlos morir. Por su lascivia y crueldad, estas criaturas infernales, capaces de transformarse en perras o vacas, se emparentaban con Lamia, la vengativa divinidad libia.

${ }^{9}$ M. Praz (1999), p. 170.

${ }^{10} \mathrm{Si}$ recordamos la archiconocida novela del irlandés Stocker, Drácula, vemos con mayor claridad cómo se ha recurrido frecuentemente a la figura del vampiro como un recurso habitual a la hora de enfrentar paganismo contra cristianismo.
} 
comparaciones entre el estereotipo de la vampira y el vampiro muestran que las distintas formas en la ficción están basadas en una valoración negativa de esa diferencia sexual y en una división binaria de la sexualidad" $"$.

Volviendo a La novia de Corinto hemos de destacar que la obra aúna por un lado la visión más clásica del motivo vampírico con una concepción profundamente romántica y moderna.

En la atracción inherente que la figura del no muerto ejerce sobre quienes están a su alrededor, encontró el Romanticismo el motivo o la excusa para tratar el tema sexual con una mayor amplitud de miras, acercándose a él desde los distintos ángulos de visión que puede ofrecer la literatura fantástica. Es a causa de esta novedosa (y hasta cierto punto aparente) liberación sexual por lo que resulta tan obvia la atracción lésbica en "Carmilla", un tema casi inexistente en la literatura anterior al siglo XX.

Ya desde el arranque del relato, la vampira inicia su cercamiento hacia Laura rodeándole el cuello con sus "bellos brazos", rozando sus labios y empleando un suave tono de voz que arrastra a la niña hacia ese universo de sensualidad y lúbrica seducción del que no puede ni quiere salir. Sin embargo, aunque la relación entre Laura y Carmilla es la más afamada en este sentido, no es la única. El trabajo inacabado "Christabel" (1797) de Samuel T. Coleridge es considerado el primer poema vampírico en lengua inglesa. En él encontramos los orígenes de la atracción lésbica de la obra de Le Fanu encarnada en los personajes de Geraldine, la bella hechicera, y Christabel, a quien la primera convence para compartir el lecho. Como destacan Ibarlucía y Castelló-Joubert "la trama de lesbianismo e incesto dejó, sin embargo, una profunda huella en la literatura de lengua inglesa del siglo XIX, como puede verse en "Carmilla" de Joseph Sheridan Le Fanu"12.

Como diversos autores han señalado, "Carmilla" cumple con todos los tópicos y rituales de la fórmula actual de la ficción vampírica: desde la estructura interna en cuanto a los cuadros en los que se divide la acción (ataque, muerte/resurrección, caza/destrucción) hasta, como hemos visto, la seducción, larga y plagada de detalles, de la víctima por parte del vampiro, la confusión entre sueño y realidad y el fracasado intento de hallar una explicación racional para los sucesos sobrenaturales acaecidos que, finalmente, pueden solventarse gracias al reconocimiento de los métodos del folklore tradicional del cazavampiros para reconocer, vencer y matar al monstruo.

Que la vampira y, por tanto, la mujer fatal (la pecadora, la prostituta, la vamp) son el principal peligro para el modo victoriano de comprender y llevar la institución del matrimonio es más que evidente en el relato atribuido a Tieck "No

\footnotetext{
${ }^{11}$ S. Lucendo (2009), p. 235.

${ }^{12}$ R. Ibarlucía y V. Castelló-Joubert (2002), p. 18.
} 
despertéis a los muertos" ${ }^{\prime 13}$. En él, el amor del protagonista junto con su inconsciencia e ignorancia le llevan a traer de vuelta de la tumba a su fallecida esposa Brunhilda, lo que termina conllevando la fatídica muerte de sus hijos a manos de la sedienta vampira (de nuevo encontramos aquí, como hemos visto y como ahondaremos en ello más adelante, el motivo de la no muerta como antitesis radical de la madre). Lo que le conduce a la ruptura inevitable del nuevo matrimonio y, finalmente, hacia su propia y horrible muerte que se resume en la inevitable advertencia: "no despertéis a los muertos".

Este juego, el favorito del gato que suelta y agarra al ratón, de tentar con lo prohibido, con lo vergonzante, con aquello que no debe ser nombrado, es también el favorito de otra dama aterradora de la literatura francesa del XIX, la cortesana Clarimonda de Gautier, quien seduce con sus artes demoníacas y su belleza sobrenatural al padre Romualdo, hombre piadoso y temeroso de Dios hasta que posa en ella sus ojos (" $i$ Piensa en ello, hermano! Por haber mirado a una mujer una sola vez, por cometer una falta aparentemente tan leve, padecí durante años los tormentos más terribles; mi vida se vio perturbada para siempre"14) y cuya alma termina por pertenecerle casi hasta la locura, hasta que, ayudado por el padre Serapione, logra vencer el poder, más emocional y sensual que puramente demoníaco, que la bellísima cortesana ejerce sobre él. Una victoria que no le causa, como vemos en otros héroes supervivientes de historias de vampiros, alegría ninguna. Hasta el final de sus días Romualdo, quien debería comportarse como una víctima liberada según los tópicos, no deja de lamentar la pérdida de su amada y de la diversión y felicidad que ella le daba. En este punto, los actos de Serapione, claro antecedente del arquetipo del cazavampiros, no le parecen destinados a salvar su alma sino únicamente a coartar su diversión: "La muerte de la vampira, y lo que ella representa frente al realismo, no ha traído en absoluto la tranquilidad al monje, sino todo lo contrario. Destruir a Clarimonda, como representante y guía dentro del mundo del placer nocturno y la fantasía, es destruir lo más interesante de la vida, según Gautier" ${ }^{\prime 15}$.

Una de las novedades más interesantes del relato de Gautier es que Clarimonda no busca de manera directa la muerte de su amado. Desde el primer momento lo que pretende es seducirle, apartarle del camino de la fe ("porque te amo y deseo arrebatarte a tu Dios, hacia el que tantos corazones vierten ríos de amor, sin alcanzarlo jamás"16), al menos al Romualdo hechizado, el vividor, mientras que su alter ego, el religioso, castiga su cuerpo con el cilicio, el ayuno y la oración en una pesadilla desdoblada en la que la duda entre realidad y ficción supone una tortura

\footnotetext{
${ }^{13}$ Aunque recientes investigaciones parecen indicar que su creador fue Ernst Raupach.

${ }^{14}$ T. Gautier (2001), p. 31.

${ }^{15}$ S. Lucendo (2009), p. 277.

${ }^{16}$ T. Gautier (2001), p. 21.
} 
constante para el alma del monje. Llega la mujer-monstruo incluso a drogarle cada noche para poder beber una gota de su sangre sin matarlo y así, de este modo, mantenerse ella con vida y alargar su pasión, en una de las escenas más sensualmente eróticas de la literatura fantástica del momento:

La sangre corrió en hilillos purpúreos y algunas gotitas salpicaron a Clarimonda. Sus ojos recuperaron entonces el brillo, y noté en su cara una expresión de feroz y salvaje alegría que hasta entonces nunca había notado. Saltó del lecho con agilidad animal - con la agilidad de un mono o de un gatoy se lanzó sobre mi herida, que succionó con indescriptible voluptuosidad. Sorbió despacio mi sangre, con la delectación de un gourmet que cata un vino de Jerez o Siracusa; entrecerraba los ojos, cuyas verdes pupilas no eran ahora redondas, sino oblongas. De vez en cuando se interrumpía para besarme la mano, después posaba sus labios sobre la herida y bebía una nueva gota. Cuando vio que la sangre cesaba de manar, se levantó con los ojos húmedos y brillantes ${ }^{17}$.

Una nueva faceta de la vampira -el alargar la vida del objeto de deseo por placer y, quizá también, para satisfacer una cierta sensación de soledad- es lo que la hace más humana, pero también, como puede observarse en el desenlace del relato, más vulnerable y más peligrosa cuando sus sentimientos resultan heridos. Para autores como Twitchell (1981), la diferencia entre el vampiro y la vampira es que en el caso de los primeros sus historias tratan sobre la dominación mientras que en las de ellas, predomina la seducción: "While the male vampire story was a tale of domination, the female version was one of seduction" $"$. Sin embargo, podemos afirmar que cierto tipo agresivo de seducción está íntimamente relacionado con la dominación. A pesar de ello, la seducción, aunque resulte ser el arma principal de la mujer vampiro no es, en ningún caso, de su exclusiva, aunque sí persistente a lo largo del tiempo y de su iconografía. Podemos contemplar una diferencia de enfoque en cuanto al estilo de seducción del hombre y la mujer vampiro: el primero diversifica más su caza (hombres, mujeres, ancianos, niños, jóvenes), mientras que la mujer tiende a establecer primero relaciones personales y familiares antes de dar muerte a su víctima -como observamos en los casos de Clarimonda y Carmilla, por ejemploy suelen atacar a jóvenes de ambos sexos y, esencialmente, a niños, en una revisión del mito de Lilith y en una perversión del papel de la mujer-madre encargada de dar vida y alimento frente a la mujer-vampira (mujer-liberada) que arranca una y toma el otro. ${ }^{19}$

\footnotetext{
${ }^{17}$ T. Gautier (2001), pp. 48-49

${ }^{18}$ J. Twitchell (1981), p. 39.

19 Tanto las tres vampiras amantes-discípulas de Drácula como la propia Lucy aparecen devorando niños en la obra, en un intento de hacer aún más repulsiva la imagen de la bella muerta para el lector victoriano.
} 
La poesía decimonónica se alimentó también del arquetipo vampírico en sus dos vertientes (masculina y femenina), aunque de manera inevitable, la lírica tendió más habitualmente a identificar la fuente del Mal con la Belleza y, por tanto, con esa imagen de la mujer aterradora que devora sin remordimientos el corazón del poeta.

La misma mujer que primero seduce y luego asesina sin el más mínimo atisbo de compasión, una mujer ante la que el escritor se siente más vulnerable y perdido que nunca, no sólo por la fuerza que ella emana sino por las características bien poco halagüeñas que suele reunir el hombre que se deja seducir por la bella difunta (cobardía, fragilidad, masoquismo...). Según esta idea, la fuerza de la vampira es directamente proporcional a la debilidad del hombre al que mata o seduce. A este tema y con este enfoque y diversas variantes dedicaron algunos poemas autores como Baudelaire ("La metamorfosis del vampiro", "El vampiro"), Keats ("Lamia", "La Belle Dame sans Merci"), Kypling ("El vampiro") y algunos relatos versificados, como "Leonora" de G.A. Bürger, donde la mujer, en este caso, es la víctima del muerto que regresa de la tumba para desposarla ${ }^{20}$.

Como podemos observar en la mayoría de estos poemas, no nos encontramos sólo ante historias, relatos de vampiras, sino que el poeta termina por atribuir a mujeres reales -mujeres letales- las características tanto físicas como psicológicas de la mujer como parásito chupasangre al que de forma inevitable y enfermiza se siente atraído, como sucede con todo aquello que representa lo más bajo de la condición humana. Resulta del todo inevitable al leer a Baudelaire establecer la conexión ya habitual entre las imágenes de vampirismo y las enfermedades de transmisión sexual, la prostitución, la liberación de las costumbres y las coacciones de todo tipo. Es por esto por lo que, pese a todo, la moral del hombre de fin de siglo debe ponerle cortapisas al monstruo que no ha de vencer nunca, bajo ningún concepto.

No puede pasar desapercibido que, en la fantasía de seducción que la vampira representa para el hombre, el sadismo y la tortura desempeñan un importante papel. No hemos de olvidar que estos mismos autores decadentes, cumpliendo con la estética decimonónica, tienden a recrearse en el sufrimiento femenino como una nueva forma estética, una nueva inspiración ${ }^{21}$. Era del todo inevitable que este sentimiento llegara hasta la figura de la vampira, en la que los hombres del relato vuelcan toda su ira, empalándola y decapitándola sistemáticamente y disfrutando de

\footnotetext{
${ }^{20}$ El famoso estribillo Laß ruhn die Toten inspiraría en 1823 el cuento de Ernst S. Raupach, "No despertéis a los muertos".

${ }^{21}$ Podemos resumir en este sentido el espíritu de fin de siglo con la frase recogida en Praz de Baculard d'Aranaud: “Que les yeux d'une amante sont ravissants, adorables, lorsqu'ils sont couverts de larmes! Le coeur s'y baigne tout entier”, “¡Los ojos de una amante son encantadores, adorables, cuando están cubiertos de lágrimas! El corazón entero se baña en ellas". M. Praz (1999), p. 68.
} 
ello sin el más mínimo resquicio de duda (no olvidemos la escena de la muerte final de Lucy en Drácula que contrasta sumamente con la tristeza de Romualdo al terminar con Clarimonda). La moraleja final es que el monstruo (hembra) siempre es sometido, lo que no sucede igual (ni en número ni en modo) con el vampiro masculino.

Como ya hemos mencionado anteriormente, existe una relación clara entre la bruja y la vampira, relación que se puede apreciar en mayor detalle poniendo en relación las historias y los personajes de La muerta enamorada y El Monje. En ambos relatos, la mujer, emparentada directamente con el Mal y poseedora de poderes sobrenaturales, corrompe al sacerdote valiéndose de su apariencia de dulce madonna medieval. En este caso, la diferencia argumental es que en El Monje, Ambrosio termina siento castigado, mientras que Romualdo se redime $\mathrm{y}$, años después, se lamenta de la pérdida de su amada. En cuanto a lo que las protagonistas representan, Matilda, encarnación de la pura maldad, está dispuesta a todo para lograr tentar a Ambrosio, para introducir a un monje virtuoso en el mundo del pecado al que el hombre termina por darse con desenfreno. Clarimonda, también agente del mal, presenta sin embargo características que podríamos llamar "más luminosas", empezando por su nombre (que el antropónimo de una vampira se refiera a la claridad del mundo no deja de ser sarcástico o, cuando menos, significativo), y siguiendo con una serie de rasgos que pueden apreciarse en la cortesana, donde podríamos aventurarnos a conjeturar que ella no es sino la encarnación del subconsciente de Romualdo, una presencia malvada que deviene de la culpa y la imaginación del propio cura y a la que, por tanto, éste no puede odiar.

Como hemos visto, Clarimonda fue la última de las bellas atroces del siglo XIX que despertó en los lectores algún tipo de simpatía. Según avanzaban el tiempo y la literatura, la vampira era cada vez más malvada y carente de matices.

La literatura posterior, en especial la literatura norteamericana del siglo XX, ahondará mucho más en la figura del vampiro al que dominan los sentimientos de soledad y desagrado, en un intento no sólo de humanizar esta figura arquetípica de la literatura de terror, sino también y sobre todo, convertirla en un icono del ser rechazado y marginado por la sociedad que, en su más profundo yo, ansía en realidad regresar a ella. Nada más alejado del papel originario de la mujer vampira, de la femme fatale que llega incluso a disfrutar del caos y la destrucción que siembra a su paso.

\section{Obras citadas}

BORNAY, Erika: Las hijas de Lilith, Madrid, Ensayos Arte Cátedra, 2004.

DIJKSTRA, Bram: Ídolos de perversidad. La imagen de la mujer en la cultura de fin de siglo, Madrid, Club de Lectores, 1994. 
FRENZEL, Elisabeth: Diccionario de motivos de la literatura universal, Madrid, Gredos, 1980.

GARCÍA, Miguel: "El hambre del "otro" o la sombra del vampiro", en Paradigma, vol.7, 2009, p. 8-14.

KEATS, John: Poesía completa. Tomo 2, Barcelona, Ediciones 29, 1978.

-----: Poemas escogidos, Madrid, Cátedra, 2007.

LUCENDO LACAL, Santiago: El vampiro como imagen-reflejo: Estereotipo del horror en la modernidad, Tesis no publicada, Madrid, UCM, 2009.

MuÑOZ ACEBES, Francisco Javier: "El motivo de la mujer vampiro en Goethe: Die Braut von Korinth" en Revista de Filología Alemana, Universidad de Valladolid, 2000, 8: 115-128

Perkowski, Jan L.: A treatise on Slavic Vampirism, Ohio, Slavica Publisher Inc, 1989.

PoE, E.A.: La filosofia de la composición y el principio poético. Madrid, Libros C. de Langre, 2001.

PRAZ, Mario: La carne, la muerte y el diablo en la literatura romántica, Barcelona, El Acantilado, 1999.

Twitchell, James R.: The living Dead. A study of the Vampire in Romantic Literature, Durham, Duke University Press, 1981.

VV. AA.: El Vampiro, Madrid, Siruela, 2001.

VV. AA.: Vampiras. Antología de relatos sobre mujeres vampiro, Madrid, Valdemar, 2001.

VV. AA.: Vampiria. Selección de Ibarlucía, Ricardo y Castello-Joubert, Valeria, Buenos Aires, Editorial de Adriana Hidalgo, 2002. 